\title{
Effect of Green Technology Investment on a Production-Inventory System with Carbon Tax
}

\author{
Tapan Kumar Datta \\ BITS Pilani, Dubai Campus, Dubai International Academic City, Dubai, UAE \\ Correspondence should be addressed to Tapan Kumar Datta; dutta@dubai.bits-pilani.ac.in
}

Received 24 June 2017; Revised 4 November 2017; Accepted 20 November 2017; Published 13 December 2017

Academic Editor: Konstantina Skouri

Copyright (C) 2017 Tapan Kumar Datta. This is an open access article distributed under the Creative Commons Attribution License, which permits unrestricted use, distribution, and reproduction in any medium, provided the original work is properly cited.

\begin{abstract}
Carbon emissions play the central role in global warming. Manufacturing firms are significant contributors to carbon emissions. In many countries, regulatory authorities are taking actions to reduce emissions. Carbon taxation and cap-and-trade schemes are two mechanisms implemented in many countries. In the present paper, the author analyzes a production-inventory model under a carbon tax system. The production rate is assumed to be a decision variable and can be set at any level within machine limits. A proportion of items produced are defective, and this proportion depends on the production rate. Demand depends on the selling price. Unit price is a decreasing function of the production rate. Emissions can be reduced to some extent by capital investment on green technology, and this capital investment amount is a decision variable. Customers are categorized as retail customers and wholesale customers. A discount is offered to the wholesale customers on the regular selling price. The results are illustrated by a numerical example and a sensitivity analysis is performed.
\end{abstract}

\section{Introduction}

Global warming is a major threat to our planet. It poses severe risk to the nature, human health, and well-being. It has many catastrophic effects, such as rise of sea level, disruption in ecosystems, flood, drought, storm [1], and increased clear-air turbulence (see Williams and Joshi [2]). The reason for global warming is emission of greenhouse gases (GHGs), such as carbon dioxide $\left(\mathrm{CO}_{2}\right)$, methane, and nitrous oxide. Among GHGs, $\mathrm{CO}_{2}$ plays main role for global warming because of its high heat-trapping property and long survival period in atmosphere. Main causes of GHG emissions are human activities, such as burning of fossil fuel for industrialization, transportation, generating electricity, and deforestation for urbanization. In addition, since the world economy depends upon the fossil fuel for industrial activities, the GHG emissions cannot be stopped completely. The primary task to mitigate global warming is to reduce the emission rate significantly.

Industry is one of the major contributors of GHG emissions. In 2014, United States Environmental Protection Agency (EPA) reported that industry was the third major contributor to GHG emissions contributing $21 \%$ of the total
GHG emissions in Unites States. Industry emissions can be reduced by efficient use of modern technologies, efficient inventory control, and wise managerial decisions during industrial activities.

Regulatory boards in many industrialized countries are taking initiatives to control emission of GHGs. Carbon tax and cap-and-trade system are two main mechanisms adopted by many countries to reduce the amount of emission. A carbon tax is a fee levied on the carbon content of the fuels. It is particularly levied on the amount of carbon dioxide emitted by burning fossil fuels. Many European countries, like Finland, Denmark, Norway, Sweden, Switzerland, Slovenia, UK, Italy, and so on, have enacted carbon tax to cut carbon emissions. The cap-and-trade mechanism is another sensible regulation policy to reduce GHG emissions. In this policy, the regulatory body first sets a maximum allowable emission limit (cap) from all possible sources, which is lowered over time, and then this amount is distributed or auctioned among the polluting entities as permits/allowances. A polluting entity must purchase permits/allowances. Polluters can trade the unused permits. The EU emissions trading system (EU ETS) is the world's first major carbon market. It operates in almost all EU countries and also in Iceland, Liechtenstein, 
and Norway [3]. The Regional Greenhouse Gas Initiative (RGGI) was the first mandatory cap-and-trade program in the United States to limit carbon dioxide (CO2) from the power sector. It is being implemented in Connecticut, Delaware, Maine, Maryland, Massachusetts, New Hampshire, New York, Rhode Island, and Vermont [4].

Three main phases of a firm's production-inventory system are ordering/setup activities, production activities, and warehousing activities. All these three phases involve carbon emission. Under carbon emission regulation policies, a firm needs to reset its optimal decision policies for production, inventory, and warehousing to reduce emission. A firm can also reduce emission significantly by investing on greener projects such as environment friendly production process (Liu et al. [5]) and greener warehousing (Ilic et al. [6]).

\section{Literature Review}

Analysis of inventory systems under carbon emission regulation policies is an emerging field of inventory management. Recently, some researchers have done significant research in this field. Bonney and Jaber [14] analyzed the impact of environmentally responsible inventory models on optimal decisions of traditional inventory models. Hua et al. [15] proposed a managerial approach to control carbon footprint in inventory management system under carbon emission trading mechanism. El Saadany et al. [16] investigated a two-echelon supply chain model with price and product's environmental quality dependent demand. Wahab et al. [17] developed a lot size inventory model with environmental considerations. Their main focus was on reducing $\mathrm{CO}_{2}$ emission in inventory transportation. Bouchery et al. [18] reformulated the classical economic order quantity model as a multiobjective problem taking sustainability concerns into account. Glock et al. [19] developed an inventory model of single product with price and quality dependent demand. They considered sustainability as a quality attribute and measured in terms of level of scraps and emission in the supply chain. Single and multistage lot sizing models with carbon emission constraints were investigated by Benjaafar et al. [20]. Chen et al. [21], in their article, provided condition for reducing emission by modifying order quantities. They also provided conditions under which relative reduction in emissions exceeds relative increase in cost. They discussed the applicability of the results under various environmental regulations: strict carbon caps, carbon tax, cap-and-offset, and cap-and-price. Battini et al. [22] investigated a singleproduct replenishment problem under traditional economic order quantity (EOQ) framework and sustainability considerations. They focused on transportation costs analysis and quantification, and external costs integration according to a life cycle assessment (LCA) approach. Zanoni et al. [23] proposed a joint economic lot size model in vendorbuyer supply chain with price and environmentally sensitive demand. Single-item, multisourcing, carbon-constrained lot size models were studied by Absi et al. [24, 25]. The impact of carbon tax and cap-and-trade mechanisms on dual-sourcing newsboy problem was studied by Rosič and Jammernegg [26]. A single period dual-sourcing inventory model with product carbon footprint constraint was studied by Arikan and Jammernegg [27].

Hovelaque and Bironneau [28] investigated an inventory system under environmental conditions in which demand was a function of both price and total carbon emission. They found that a carbon tax was always beneficial to the environment. Dye and Yang [29] analyzed sustainable inventory models with trade credit. They discussed the models under various environmental regulations. Chen and Hao [30] used game theory models to derive competing firms' optimal pricing and production policies under carbon dioxide emission tax mechanism. They showed that when the two competing firms paid the same carbon emissions tax, both of them set higher retail price than those that did not pay carbon emissions tax. They also found that the percentage reduction of profit and carbon emission of a high-efficiency firm were lesser than that of low-efficiency firm. Martí et al. [31] proposed a supply chain network model with demand uncertainty which includes supply chain responsiveness decisions under different carbon policies. They also showed the effect of different carbon policies on supply chain costs and network design. García-Alvarado et al. [32] developed a finite horizon stochastic closed-loop inventory model with two environmental constraints: capand-trade and minimal remanufacturing requirement. They applied periodic review system with discrete time. Hong et al. [33] proposed a dual mode production planning system with emission constraints. They assumed that the manufacturer was equipped with regular and green production technologies to satisfy the emission limitations. Bazan et al. [34] developed a manufacturing/remanufacturing inventory model with waste disposal. They considered tax penalty for emission. They also claimed that their model was the preliminary step for developing an environmentally responsible reverse logistics inventory model. Chang et al. [35] studied a hybrid manufacturing-remanufacturing system under capand-trade mechanism.

There are many imperfect production/manufacturing systems which partially produce defective goods together with perfect goods (see Papachristos and Konstantaras [36], Ben-Daya et al. [37], Eroglu and Ozdemir [38], Datta [39, 40], Lo et al. [41], Khan et al. [42], J.-T. Hsu and L.-F. Hsu [43], Mandal and Giri [44], Sana [45], and Lai et al. [46]). These defective goods are responsible for emissions during their production and disposal phases. Analysis of such imperfect production systems with sustainability considerations would be of great interest. Mukhopadhyay and Gowsami [7] developed a model of production-inventory system with pollution cost and partially imperfect products in which a proportion of imperfect products are reworkable. They considered constant demand rate and constant production rate.

Toptal et al. [8] analyzed a retailer's joint decisions on inventory replenishment and carbon emission reduction investment under three carbon emission regulation policies. They considered carbon emissions reduction investment availability under carbon cap, tax, and cap-and-trade policies. Lou et al. [9] developed a supply chain model with investment in emission reduction technology. They analyzed the consequences of emission trading policy on supply chain 
decisions. Recently, Lin and Sarker [10] described a pull system inventory model in which they employed an order overlapping scheme to avoid shortages. They considered an imperfect production system with constant demand rate. $\mathrm{Hu}$ and Zhou [11] designed a decision support system which examined the manufacturer's joint emission reduction efforts and pricing decision under carbon trading policy. Sana et al. [12] analyzed an imperfect production system with finite production rate. They considered the unit cost as a decreasing function of production rate. Their model does not include the impact of carbon emissions. Manna et al. [13] developed a model with imperfect production system and production rate dependent unit cost. They considered the defective proportion as an increasing function of the production rate. Their model does not consider emissions.

In the present article, the author addresses the effects of carbon tax and green investment on a more general production-inventory system with selling price dependent demand and variable production rate. The system produces defective items, and the defective proportion depends on the production rate. Unit cost is a function of production rate. Customers are categorized as retail customers and wholesale customers. A fixed discount on the regular selling price is offered to the wholesale customers. As far as the author's knowledge is concerned, none of the existing models available in literature considers all these realistic factors in a single model. Profit maximization policy is considered to solve the model with four decision variables: selling price, production rate, green investment amount, and optimum production run-time in each cycle. Later, emission minimization policy is considered to compare the results. To justify the importance of the proposed model, a comparison of this model with some of the related published works is shown in Table 1. Rest of the paper is organized as follows. Section 3 describes the basic assumptions and notations. In Section 4, mathematical model of the proposed system is developed. Solution procedure and algorithm are presented in Section 5. Section 6 contains numerical examples. Sections 7 and 8 present sensitivity analysis and concluding remarks, respectively.

\section{Assumptions and Notations}

\subsection{Assumptions}

(i) Demand rate is a linearly decreasing function of selling price. A proportion of demand is generated by retail customers and rest by wholesale customers. Wholesale customers get a fixed discount on the regular selling price.

(ii) Shortages are not permitted.

(iii) Production rate per unit time is finite and can be set at any level within machine limits. Production rate is a decision variable.

(iv) A proportion of items produced are defective/imperfect. This proportion is an increasing function of production rate because the reliability may decrease with increasing production rate (see Manna et al. [13]). During production, an automated system will detect and separate the defective items immediately. Defective items are nonrepairable and are outsourced to a third party disposal agency for disposal (see Datta [40]). So, inventory will be maintained for good quality items only.

(v) Unit cost is assumed to be a decreasing function of production rate. It happens in many industries due to economies of scale (see Sana et al. [12] and Manna et al. [13]). Unit cost consists of two cost components: one is fixed cost which incurs due to raw materials, assembling, and so on, and the other component is variable cost which incurs due to energy, labor cost, rent, insurance, and so on. The variable cost is a decreasing function of production rate. In the present article, the unit cost is considered as a negative exponential function of production rate.

(vi) Time horizon is infinite.

(vii) Carbon emission takes place during three phases of the system: production, storage, and disposal of defective items. There are three sources of emissions in the production phase. First source is production setup which emits a constant amount of $\mathrm{CO}_{2}$ in a production cycle (Hovelaque and Bironneau [28]). Second source is production process which may involve smelting, assembling, chemical reactions, and so on. The amount of emission from this source depends on the production rate/level. Third source is basic machining operations which depends on time during which production process runs. Emissions during storage depend on the quantity and the time during which it is stored. Emission during disposal depends on the quantity of disposed items.

(viii) A carbon tax is levied on each unit of carbon emitted.

(ix) Manufacturer has a plan to move towards a greener production system by investing on advance technology, energy efficient machineries, nonconventional energy, and so on. There is a ceiling on the investment amount. This ceiling is the manufacturer's budget on modernization project towards green technology.

\subsection{Notations}

\subsubsection{Decision Variables}

$s_{p}$ : Selling price per unit.

$P$ : Production rate per unit time which can be set at any level in $P_{\min } \leq P \leq P_{\max }$.

$t_{1}$ : Production run-time in a production cycle.

$K$ : Amount of capital investment on green technology for reducing emission.

\subsubsection{Model Parameters}

$D\left(s_{p}\right)$ : Demand rate per unit time which is taken in the linear form $D\left(s_{p}\right)=\alpha-\beta s_{p}$, where $\alpha, \beta$ are positive constants with $s_{p}<\alpha / \beta$. 


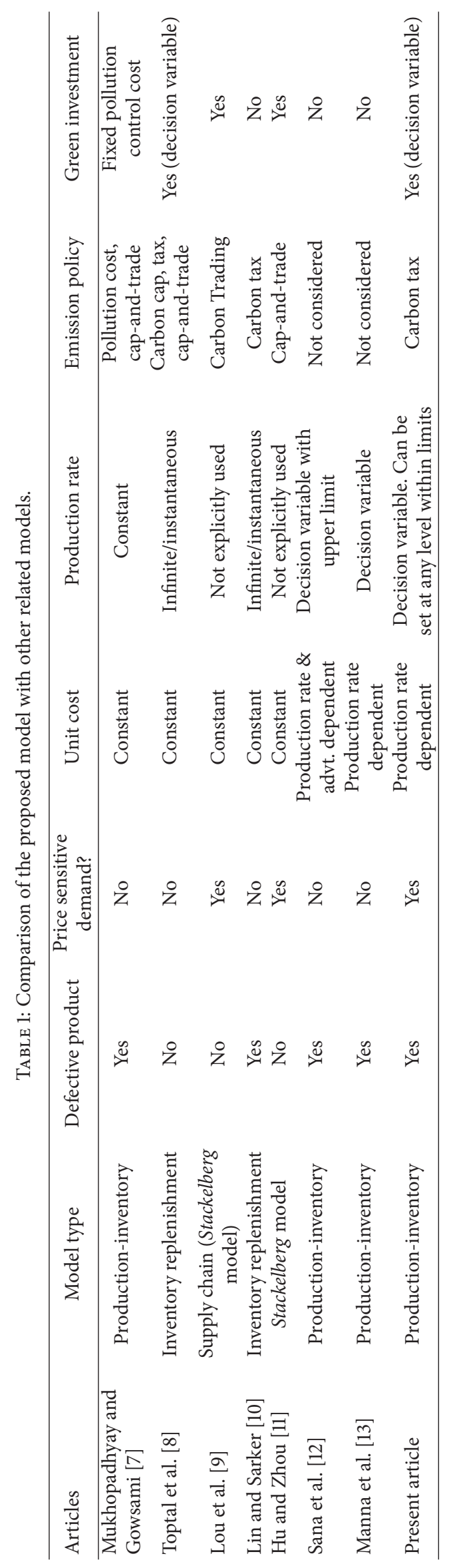


$\gamma$ : Proportion of demand generated by retail customers. Hence, $(1-\gamma)$ proportion of demand is generated by wholesale customers.

$(1-\delta) \times 100 \%$ : Discount percentage on selling price offered to wholesale customers.

$\lambda(P)$ : Proportion of defective items produced at production level $P \cdot \lambda(P)$ is taken in the linear form $\lambda(P)=$ $\lambda_{1}+\lambda_{2}\left(\left(P-P_{\min }\right) /\left(P_{\max }-P_{\min }\right)\right)$, where $\lambda_{1}$ and $\lambda_{1}+\lambda_{2}$ are the lower and upper bounds of the proportion of defectives. Mathematically, $0 \leq \lambda_{1} \leq \lambda(P) \leq$ $\lambda_{1}+\lambda_{2}<1$. The reason for taking $\lambda(P)$ in this form is to ensure that the second term of the right hand side is a fraction. However, one can take it in the simple linear form $\lambda(P)=\lambda_{1}+\lambda_{2} P$, where $0 \leq \lambda_{1} \leq$ $\lambda_{1}+\lambda_{2} P_{\max }<1$. $\lambda_{2}=0$ describes the situation that a constant proportion of items produced is defective.

$L$ : Quantity of good items produced per unit time. Assume $L=\{1-\lambda(P)\} P>D\left(s_{p}\right)$ because the production rate of good items should exceed the demand rate. This assumption is very common in inventory literature. $L>D\left(s_{p}\right) \Rightarrow s_{p}>(\alpha-L) / \beta$.

$C_{h}$ : Holding cost per unit per unit time.

$\mathrm{C}_{s}$ : Setup/ordering cost per production run.

$C_{d}$ : Disposal cost per unit.

$C_{t}$ : Carbon tax per unit of carbon emitted.

$C_{u}(P)$ : Unit cost, taken in the exponential form $C_{u}(P)=m_{1}+m_{2} e^{-m_{3}\left(P-P_{\min }\right)}, m_{1}, m_{2}, m_{3}>0$, where $m_{1}$ is the fixed cost component and $m_{2}$ and $m_{3}$ are the scale and shape parameters of variable cost component. Upper bound of the unit cost is $m_{1}+m_{2}$. Unit cost attains the upper bound when the production level is set at $P_{\min }$. By substituting $m_{2}=0$, we can get the constant unit cost case.

$a$ : Amount of emission per production run due to setup, which is constant per production run.

$b$ : Average emission per unit of production during production process.

$f$ : Average emission per unit item per unit time for storing in warehouse.

$h$ : Average emission per unit of production run-time generated due to machining operations.

$g$ : Average emission per unit for disposal of defective item.

$K_{\max }$ : Manufacturer's budget for investing on green technology/modernization project. Obviously, $0 \leq$ $K \leq K_{\max }$.

$\theta$ : Maximum fraction of emission that can be reduced by investing on green technology, $0<\theta<1$.

$R=\theta\left(1-e^{-m K}\right)$ : Fraction of reduction of average emission when $K$ amount of capital is invested on green technology, $m \geq 0$. This implies that $K=$ $-(1 / m) \ln (1-R / \theta)$. This relation is analogous to the relation considered by Lou et al. [9]. The fraction of reduction $R$ is 0 , when $K=0$, and tends to $\theta$ when $K$ tends to infinity. Lou et al. [9] took $\theta=1$. The parameter $m$ reflects the efficiency of greener technology in reducing emission.

$\tau$ : Length of a production cycle, $\tau \geq t_{1}$.

\subsubsection{Other Notations}

$E\left(S ; s_{p}, P\right):$ Average emission per unit time in a production run without green investment.

PR: Average profit per unit time in a production cycle.

$S$ : Maximum level of inventory in a cycle which is attained at time $t_{1}$.

$\bar{s}=\max ((\alpha-L) / \beta, 0)$.

$(\cdot)^{*}$ : The most economic (optimum) value of $(\cdot)$.

\section{Model Development}

Production starts at time $t=0$ and continues till time $t=t_{1}$ when the stock level attains the maximum level $S$. Inventory level increases during $\left[0, t_{1}\right]$ at the rate of $L-D\left(s_{p}\right)$. During $\left[t_{1}, \tau\right]$, inventory level decreases due to demand and becomes zero at time $\tau$. The time interval $[0, \tau]$ defines a complete production cycle.

The following relations can be easily derived:

$$
\begin{aligned}
t_{1} & =\frac{S}{L-D\left(s_{p}\right)}, \\
\tau & =\frac{L S}{D\left(s_{p}\right)\left\{L-D\left(s_{p}\right)\right\}} .
\end{aligned}
$$

\subsection{Calculation of Amount of Emission}

Total emission during production process $=a+b t_{1} P+$ $h t_{1}$.

Total emission for stock holding in warehouse $=$ $0.5 S f \tau$.

Total emission for disposal $=g \lambda(P) P t_{1}$.

Average emission per unit time during a production cycle is

$$
E\left(S ; s_{p}, P\right)=\frac{\left(a+b t_{1} P+h t_{1}+0.5 f S \tau+g \lambda(P) P t_{1}\right)}{\tau} .
$$

Using relations (1), the following simplified form is obtained:

$$
\begin{aligned}
E\left(S ; s_{p}, P\right)= & \frac{a D\left(s_{p}\right)\left\{L-D\left(s_{p}\right)\right\}}{L S} \\
& +\frac{[\{b+\lambda(P) g\} P+h] D\left(s_{p}\right)}{L}+0.5 f S .
\end{aligned}
$$

Due to capital investment of amount $K$ on green technology, this average reduces to

$$
\begin{aligned}
& \left\{\theta e^{-m K}+(1-\theta)\right\} E\left(S ; s_{p}, P\right) \\
& \quad=\left\{1-\theta\left(1-e^{-m K}\right)\right\} E\left(S ; s_{p}, P\right) .
\end{aligned}
$$




\subsection{Cost and Profit Calculations in a Production Cycle}

Setup/ordering cost $=C_{s}$.

Unit cost $=C_{u}(P) P t_{1}$.

Holding cost $=0.5 C_{h} S \tau$.

Disposal cost $=C_{d} \lambda(P) P t_{1}$.

Amount of capital invested on green technology $=K$.

Average carbon tax per unit time in a cycle $=C_{t}\{1-$ $\left.\theta\left(1-e^{-m K}\right)\right\} E\left(S ; s_{p}, P\right)$.

Gross revenue $=s_{p} L t_{1}\{\gamma+(1-\gamma) \delta\}$.

Average profit per unit time in a production cycle is

$$
\begin{aligned}
\operatorname{PR} & \left(S, K, s_{p}, P\right) \\
= & \frac{s_{p} L t_{1}\{\gamma+(1-\gamma) \delta\}}{\tau} \\
& -\frac{\left[C_{s}+C_{u}(P) P t_{1}+0.5 C_{h} S \tau+C_{d} \lambda(P) P t_{1}+K\right]}{\tau} \\
& -C_{t}\left\{1-\theta\left(1-e^{-m K}\right)\right\} E\left(S ; s_{p}, P\right) .
\end{aligned}
$$

On simplification,

$$
\begin{aligned}
\operatorname{PR} & \left(S, K, s_{p}, P\right)=s_{p} D\left(s_{p}\right)\{\gamma+(1-\gamma) \delta\} \\
- & \frac{\left[C_{s}+K+a C_{t}\left\{1-\theta\left(1-e^{-m K}\right)\right\}\right]\left\{L-D\left(s_{p}\right)\right\} D\left(s_{p}\right)}{L S} \\
& -\left[C_{u}(P)+C_{d} \lambda(P)\right. \\
& \left.+(b+\lambda(P) g) C_{t}\left\{1-\theta\left(1-e^{-m K}\right)\right\}\right]\left(\frac{P D\left(s_{p}\right)}{L}\right) \\
& -\frac{D\left(s_{p}\right) h C_{t}\left\{1-\theta\left(1-e^{-m K}\right)\right\}}{L}-0.5\left[C_{h}\right. \\
& \left.+f C_{t}\left\{1-\theta\left(1-e^{-m K}\right)\right\}\right] S .
\end{aligned}
$$

The model is solved under profit maximization policy. Later, it is compared with emission minimization policy.

In profit maximization policy, the manufacturer's primary goal is to maximize his net profit.

4.3. Profit Maximization Policy. In this policy, the decision variables are $S, K, s_{p}$, and $P$, and the objective function is $\operatorname{PR}\left(S, K, s_{p}, P\right)$.

The optimization problem in this policy is

$$
\begin{array}{ll}
\text { Maximize } & \operatorname{PR}\left(S, K, s_{p}, P\right) \\
\text { subject to } & S \geq 0, \\
& 0 \leq K \leq K_{\max }, \\
& \bar{s}<s_{p}<\frac{\alpha}{\beta}, \\
& P_{\min } \leq P \leq P_{\max } .
\end{array}
$$

4.4. Emission Minimization Policy. In this policy, profit is secondary and the sole objective is to minimize the average emission per unit time. Only $S$ is treated as decision variable. The other variables $s_{p}$ and $P$ are kept at optimum values $s_{p}^{*}$ and $P^{*}$ obtained from profit maximization policy. Hence, the optimization problem is

$$
\begin{aligned}
& \text { Minimize } E\left(S ; s_{p}^{*}, P^{*}\right) \\
& \text { subject to } S \geq 0
\end{aligned}
$$

\section{Solution Procedure}

5.1. Profit Maximization Policy. For given $s_{p}$ and $P$, the necessary conditions for existence of optimum solution of optimization problem (7) are

$$
\frac{\partial \mathrm{PR}}{\partial S}=0
$$$$
\frac{\partial \mathrm{PR}}{\partial K}=0
$$

$$
\partial \mathrm{PR} / \partial S=0 \text { gives }
$$

$S$

$$
\begin{aligned}
& =\sqrt{\frac{2 D\left(s_{p}\right)\left\{L-D\left(s_{p}\right)\right\}\left(C_{s}+K+a C_{t}\left\{1-\theta\left(1-e^{-m K}\right)\right.\right.}{L\left(C_{h}+f C_{t}\left\{1-\theta\left(1-e^{-m K}\right)\right\}\right)}} \\
& \partial \mathrm{PR} / \partial K=0 \text { gives } \\
& K=\frac{1}{m} \ln \left[\frac { m \theta C _ { t } } { L - D ( s _ { p } ) } \left\{a\left\{L-D\left(s_{p}\right)\right\}\right.\right. \\
& \left.\left.+\{b+\lambda(P) g\} P S+h S+\frac{L S^{2} f}{2 D\left(s_{p}\right)}\right\}\right] .
\end{aligned}
$$

The most economic values of $S$ and $K$ for given $P$ and $s_{p}$ can be obtained by solving (10) and (11) simultaneously. In (11), if the expression inside the square bracket "[ ]" is a fraction, then the value of $K$ becomes negative. In this case, take $K=0$, because green investment will not be beneficial from profit point of view. Most economic value of $S$, in this case, can be directly obtained from equation (10) by substituting $K=$ 0 . If $\operatorname{PR}\left(S^{*}, K^{*}, P^{*}, s_{p}^{*}\right) \geq \operatorname{PR}\left(S, K, P, s_{p}\right)$ for all $S, K, P, s_{p}$ satisfying the constraints stated in (7), then the optimum solution is $\left(S, K, P, s_{p}\right)=\left(S^{*}, K^{*}, P^{*}, s_{p}^{*}\right)$. 
Hence,

$$
S^{*}=\sqrt{\frac{2 D\left(s_{p}^{*}\right)\left\{L^{*}-D\left(s_{p}^{*}\right)\right\}\left(C_{s}+K^{*}+a C_{t}\left\{1-\theta\left(1-e^{-m K^{*}}\right)\right\}\right)}{L^{*}\left(C_{h}+f C_{t}\left\{1-\theta\left(1-e^{-m K^{*}}\right)\right\}\right)}} .
$$

Theorem 1. Given $K, P$, and $s_{p}$, the profit function $P R$ is a concave function of $S$.

Proof. The condition for the concavity is $\partial^{2} \mathrm{PR} / \partial S^{2}<0$. Here,

$$
\begin{aligned}
& \frac{\partial^{2} \mathrm{PR}}{\partial S^{2}} \\
& =-\frac{2 D\left(s_{p}\right)\left\{L-D\left(s_{p}\right)\right\}\left(C_{s}+K+a C_{t}\left\{1-\theta\left(1-e^{-m K}\right)\right\}\right)}{L S^{3}}
\end{aligned}
$$

$<0$.

Hence, $\mathrm{PR}$ is a concave function of $S$ for any given $K, P$, and $s_{p}$.

Theorem 2. Given $S, P$, and $s_{p}$, the profit function $P R$ is a concave function of $K$.

The condition for the concavity is $\partial^{2} P R / \partial K^{2}<0$.

Here,

$$
\begin{aligned}
& \frac{\partial^{2} P R}{\partial K^{2}}=-\frac{m^{2} C_{t} \theta e^{-m K}}{2 L S}\left[2 a D\left(s_{p}\right)\left\{L-D\left(s_{p}\right)\right\}\right. \\
& \left.\quad+2\{b+\lambda(P) g\} D\left(s_{p}\right) P S+2 h D\left(s_{p}\right) S+L S^{2} f\right] \\
& \quad<0 .
\end{aligned}
$$

Hence, $P R$ is a concave function of $K$ for any given $S, P$, and $s_{p}$, hence, proved.

For given values of $P$ and $s_{p}$, the sufficient conditions for concavity of $P R$ are

$$
\begin{aligned}
& \frac{\partial^{2} P R}{\partial S^{2}}<0, \\
& \frac{\partial^{2} P R}{\partial K^{2}}<0, \\
& \frac{\partial^{2} P R}{\partial S^{2}} \cdot \frac{\partial^{2} P R}{\partial K^{2}}-\left\{\frac{\partial^{2} P R}{\partial S \partial K}\right\}^{2}>0 .
\end{aligned}
$$

Equations (13) and (14) show that the first two conditions are true. An analytical proof of the third condition is very difficult due to the presence of complicated terms. However, this condition is proved true in the numerical example provided in Section 6.

The following algorithm can be used to find the optimum solution of profit maximization policy.
Algorithm 3.

Step 1. Input the model parameters:

$$
a, b, f, g, h, m, C_{s}, C_{t}, C_{h}, C_{d}, \alpha, \beta, \lambda_{1}, \lambda_{2}, \theta, P_{\min }, P_{\max },
$$

$\delta, \gamma, m_{1}, m_{2}, m_{3}$.

Step 2. Set step size of $P$, say $x$, and step size of $s_{p}$, say $z$.

Step 3. Set $P=P_{\min }$.

Step 4. Define $\lambda=\lambda_{1}+\lambda_{2}\left(\left(P-P_{\min }\right) /\left(P_{\max }-P_{\min }\right)\right)$ and $C_{u}=m_{1}+m_{2} e^{-m_{3}\left(P-P_{\min }\right)}$.

Step 5. Define $L=(1-\lambda) P$.

Step 6. Set $s_{p}=\bar{s}$.

Step 7. Define the demand rate $D=\alpha-\beta s_{p}$.

Step 8. Set $K=0$.

Step 9. Calculate $S$ by (10).

Step 10. Calculate $K$ by (11).

Step 11. If $K<0$, take $K=0$ and go to Step 13. Else go to Step 12 .

Step 12. Repeat Steps 9 and 10 until the values of $S$ and $K$ become stable. Let this value of $K$ be $K_{1}$.

Step 13. $K=\min \left[K_{1}, K_{\max }\right]$.

Step 14. Calculate $\operatorname{PR}\left(S, K, s_{p}, P\right)$ by (6).

Step 15. If $s_{p}+z<\alpha / \beta$, then $s_{p}=s_{p}+z$ and go to Step 7. Else go to the next step.

Step 16. Compare the above values of $\operatorname{PR}\left(S, K, s_{p}, P\right)$ for different values of $s_{p}$. Store the maximum value ( $\overline{\mathrm{PR}}$, say) and also store the corresponding values of the decision parameters $S, K, s_{p}$, and $P$.

Step 17. If $P+x \leq P_{\max }$, then $P=P+x$ and go to Step 4. Else go to the next step.

Step 18. Compare the $\overline{\mathrm{PR}}$ values for different $P$ values. $\mathrm{PR}^{*}=\max \overline{\mathrm{PR}}$. Store this optimum solution. Also store the corresponding $S, K, s_{p}$, and $P$ values and rename them as $S^{*}$, $K^{*}, s_{p}^{*}$, and $P^{*}$.

Step 19. Find the corresponding emission quantity per unit time $e^{-m K^{*}} E\left(S^{*} ; s_{p}^{*}, P^{*}\right)$, where $E\left(S ; s_{p}, P\right)$ is given by (3).

Step 20. Stop. 
In the above algorithm, Steps 8-14 give the optimum solution for the assigned values of $P$ and $s_{p}$ as mentioned in Steps 3 and 6, respectively. Steps 6-16 give the optimum solution for the assigned value of $P$ as mentioned in Step 3. Final optimum solution will be obtained at the end of Step 19. Steps 8, 9, 10, and 12 are actually 2 -stage iterative procedures derived from (10) and (11).

5.2. Emission Minimization Policy. Given $P$ and $s_{p}$, the necessary condition for $E\left(S ; s_{p}, P\right)$ to be minimum is $d E\left(S ; s_{p}, P\right) / d S=0$.

This gives

$$
S^{*}=\sqrt{\frac{2 a D\left(s_{p}\right)\left\{L-D\left(s_{p}\right)\right\}}{f L}} .
$$

Also,

$$
\frac{d^{2} E\left(S ; s_{p}, P\right)}{d S^{2}}=\frac{2 a D\left(s_{p}\right)\left\{L-D\left(s_{p}\right)\right\}}{L S^{3}}>0 .
$$

Hence, $E\left(S ; s_{p}, P\right)$ has a unique minimum value at $S=S^{*}$ given by (16).

Optimum (minimum) average emission per unit time is obtained as

$$
\begin{aligned}
E\left(S ; s_{p}, P\right)= & \sqrt{\frac{2 a f D\left(s_{p}\right)\left\{L-D\left(s_{p}\right)\right\}}{L}} \\
& +\frac{\{(b+\lambda(P) g) P+h\} D\left(s_{p}\right)}{L} .
\end{aligned}
$$

If $P$ and $s_{p}$ are set at their optimum values $P^{*}$ and $s_{p}^{*}$ obtained in profit maximization policy, then

$$
\begin{aligned}
& S^{*}=\sqrt{\frac{2 a D\left(s_{p}^{*}\right)\left\{L^{*}-D\left(s_{p}^{*}\right)\right\}}{f L^{*}}} \\
& \text { where } L^{*}=\left\{1-\lambda\left(P^{*}\right)\right\} P^{*} .
\end{aligned}
$$

In this policy, it can be observed that $S^{*}$ does not depend on investment amount $K$ because the cost is secondary. Thus, one should invest maximum possible amount $\left(K_{\max }\right)$ to reduce emission. Hence, $K^{*}=K_{\max }$. After green investment, the emission quantity is $\left\{1-\theta\left(1-e^{-m K_{\max }}\right)\right\} E\left(S^{*} ; s_{p}^{*}, P^{*}\right)$. Instead, if the manufacturer invests the same amount $K^{*}$ as obtained in profit maximization policy, then the emission quantity becomes $\left\{1-\theta\left(1-e^{-m K^{*}}\right)\right\} E\left(S^{*} ; s_{p}^{*}, P^{*}\right)$. Equating the value of $S^{*}$ given by (12) and (19), we obtain

$$
\frac{C_{s}+K^{*}}{C_{h}}=\frac{a}{f}
$$

The average cost per unit time and the average emission per unit time will be simultaneously minimized by the same $S$ only when (20) is satisfied. If no capital is invested on green technology $\left(K^{*}=0\right)$, then $(20)$ becomes $C_{s} / C_{h}=a / f$ which agrees with Hovelaque and Bironneau [28].

Theorem 4. Let $s_{p}, K$, and $P$ be constants. The profit maximization policy will tend to the emission minimization policy as $C_{t} \rightarrow \infty$.

Proof. In profit maximization policy, for given values of $s_{p}$, $K$, and $P$, the optimum value of $S$ is

$$
\begin{aligned}
S & =\sqrt{\frac{2 D\left(s_{p}\right)\left\{L-D\left(s_{p}\right)\right\}\left(C_{s}+K+a C_{t}\left\{1-\theta\left(1-e^{-m K}\right)\right\}\right)}{L\left(C_{h}+f C_{t}\left\{1-\theta\left(1-e^{-m K}\right)\right\}\right)}} \quad \text { (from equation (10)) } \\
& =\sqrt{\frac{2 D\left(s_{p}\right)\left\{L-D\left(s_{p}\right)\right\}\left[\left(C_{s}+K\right) / C_{t}+a\left\{1-\theta\left(1-e^{-m K}\right)\right\}\right]}{L\left[C_{h} / C_{t}+f\left\{1-\theta\left(1-e^{-m K}\right)\right\}\right]}}
\end{aligned}
$$

Taking limit as $C_{t} \rightarrow \infty$, we obtain $\lim _{C_{t} \rightarrow \infty} S=$ $\sqrt{2 a D\left(s_{p}\right)\left\{L-D\left(s_{p}\right)\right\} / f L}$ which is the same as $S^{*}$ of emission minimization policy given by (16). Further, if $C_{t} \rightarrow \infty$, then from (11), $K \rightarrow \infty$. In this situation, $K^{*}=K_{\max }$ by Step 13 of the solution algorithm. This value agrees with the corresponding value of emission minimization policy, hence, proved.

\section{Numerical Example}

The input parameters of a manufacturing system are given in Table 2 (time in year, costs in \$, and emissions in ton).

Optimum results of the profit maximization policy are given in Table 3.
It can be observed that green investment has increased the profit by $40.28 \%$ and decreased the emission by $40.39 \%$.

In emission minimization policy, $s_{p}, P$, and $K$ are set at their optimum values obtained in profit maximization policy. The results of emission minimization policy are given in Table 4.

Table 5 shows the rates of reduction of profit $(\mathrm{PR})$ and emission quantity $(E)$ in emission minimization policy with respect to profit maximization policy.

\section{Sensitivity Analysis}

In this section, a sensitivity analysis is performed to study the effect of changes in carbon tax $\left(C_{t}\right)$ and production rate $(P)$ on the optimum profit $\left(\mathrm{PR}^{*}\right)$ and the emission 
TABLE 2: Input parameters.
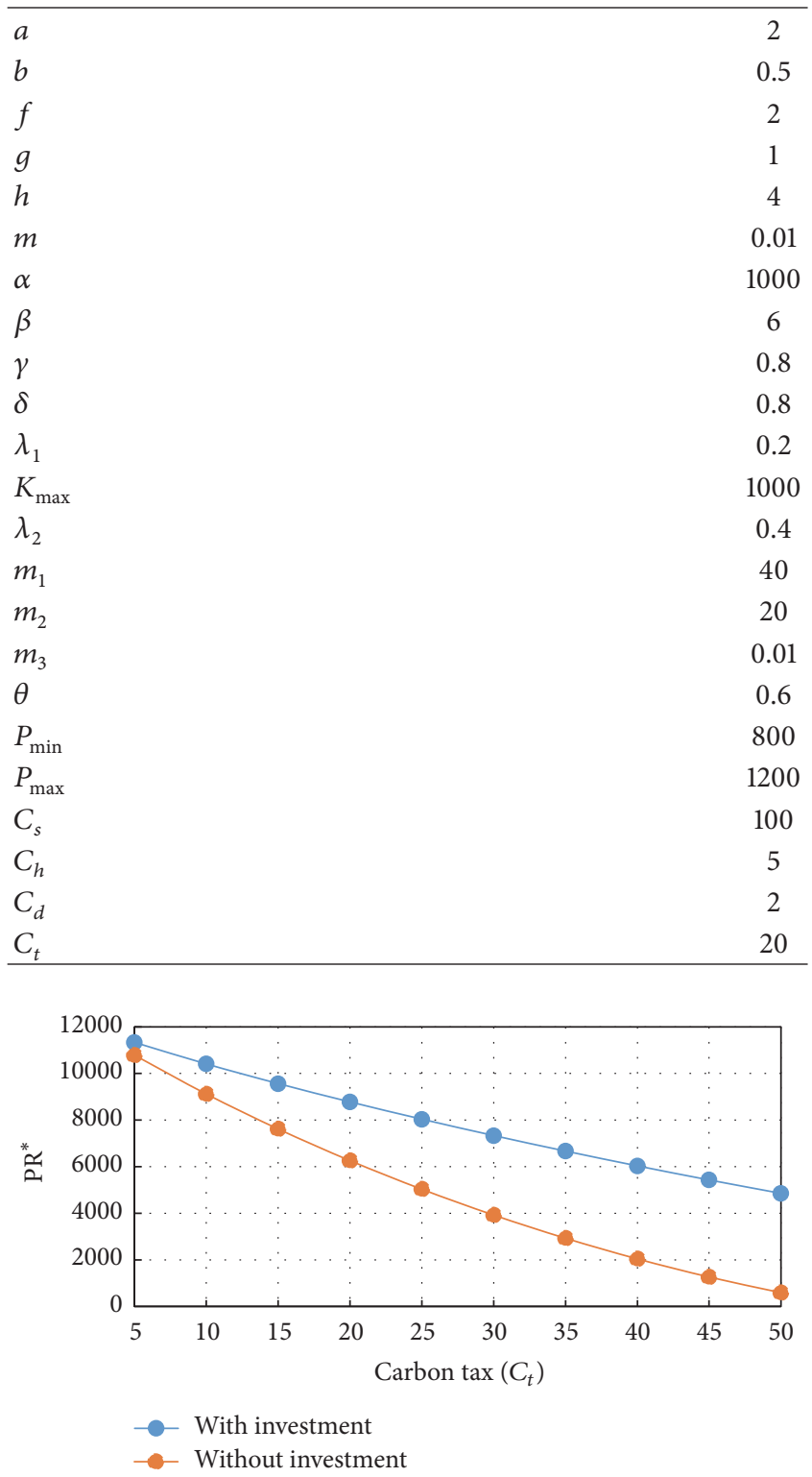

Figure 1: $C_{t}$ versus PR*

quantity $(E)$. Only one parameter is changed at a time. Other parameters are kept at their optimum values. The results are shown graphically for better understanding (Figures 1-4). In all the figures, results with green investment $(K>0)$ are compared with the corresponding results without green investment $(K=0)$. All these results are derived based on profit maximization policy.

The following characteristics of the system are observed from Figures 1-4:

(a) Green investment increases optimum profit (Figures 1 and 3 ) and reduces emission (Figures 2 and 4).

(b) An increase in the carbon tax always reduces carbon emission. This fact justifies the emission policy of imposing carbon tax to reduce emission (Figure 2).
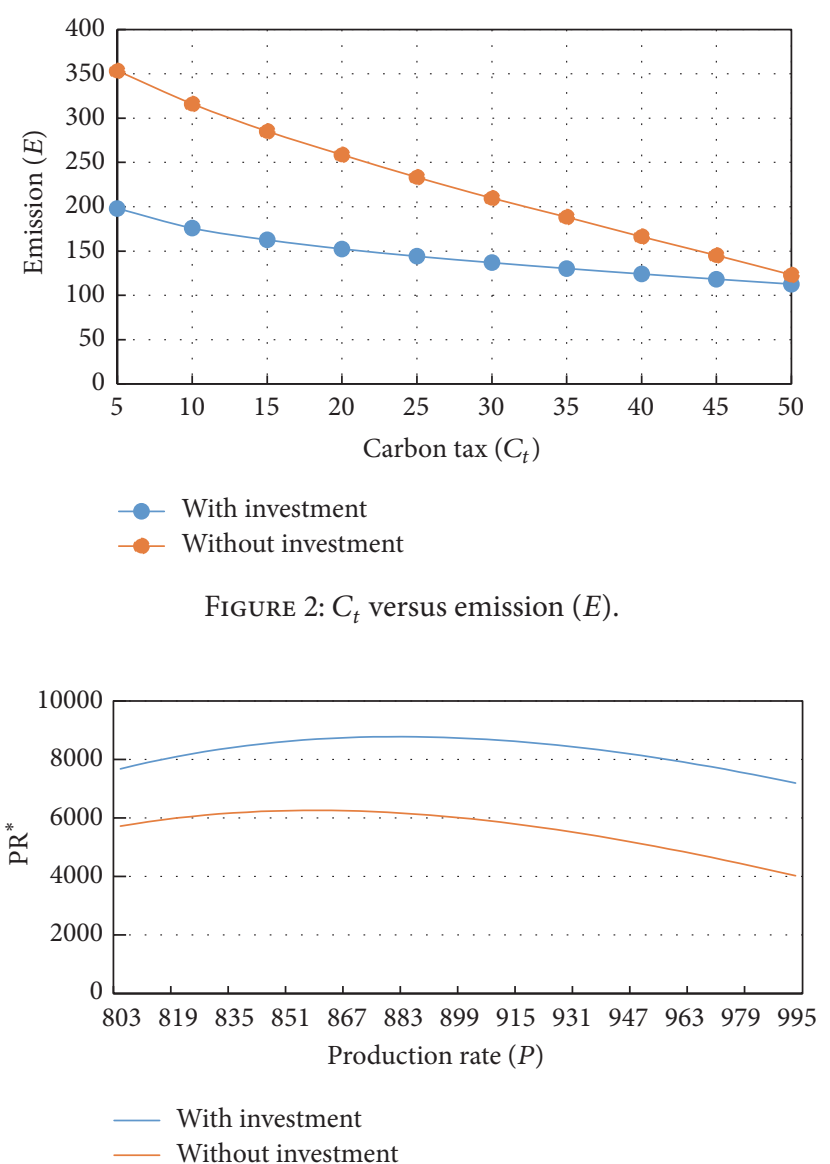

FIgURe 3: $P$ versus $P^{*}$.

(c) If carbon tax increases, the optimum profit decreases (Figure 1).

(d) Relative reduction in emission with green investment is more effective for low carbon tax (Figure 2). For high carbon tax, this relative reduction is very low.

(e) Relative increase in optimum profit by green investment is more effective for high carbon tax (Figure 1). For low carbon tax, the relative increase in optimum profit is very low.

(f) Optimum profit is a concave function of production rate both with and without green investment (Figure 3).

(g) Emission quantity is also a concave function of production rate both with and without green investment (Figure 4).

\section{Conclusions}

Carbon emission is inevitable in every production/manufacturing system. Machining operations, chemical reactions, storage, and transportation are the main activities which emit carbon to a significant quantity. This model presents a detailed analysis of how a decision maker should change his optimal policy in an inventory system under carbon tax levied by emission regulatory authority. Capital investment on green 
TABLE 3: Optimum results of profit maximization policy.

\begin{tabular}{lccccccc}
\hline & $S^{*}$ & $K^{*}(\$)$ & $P^{*}$ & $s_{p}^{*}(\$)$ & PR $^{*}(\$)$ & $E$ (tons) & Hessian \\
\hline With investment & 76.276 & 306.64 & 881 & 124.59 & 8781.51 & 152.379 \\
Without investment & 29.614 & 0.00 & 858 & 131.56 & 6259.94 & 255.634 & 0.09843 \\
\hline
\end{tabular}

TABLE 4: Optimum results of emission minimization policy.

\begin{tabular}{lcccccc}
\hline & $S^{*}$ & $K(\$)$ & $P$ & $s_{p}(\$)$ & PR (\$) & $E^{*}($ tons $)$ \\
\hline With investment & 17.391 & 305.71 & 881 & 125.09 & 6593.36 \\
Without investment & 16.790 & 0.00 & 858 & 131.18 & 6039.54 \\
\hline
\end{tabular}

TABLE 5: Rates of reduction of PR and $E$ in emission minimization policy.

\begin{tabular}{lcc}
\hline & $\begin{array}{c}\text { Reduction \% } \\
\text { (with investment) }\end{array}$ & $\begin{array}{c}\text { Reduction \% } \\
\text { (without investment) }\end{array}$ \\
\hline PR & $24.91 \%$ & $3.52 \%$ \\
$E$ & $13.63 \%$ & $2.17 \%$ \\
\hline
\end{tabular}

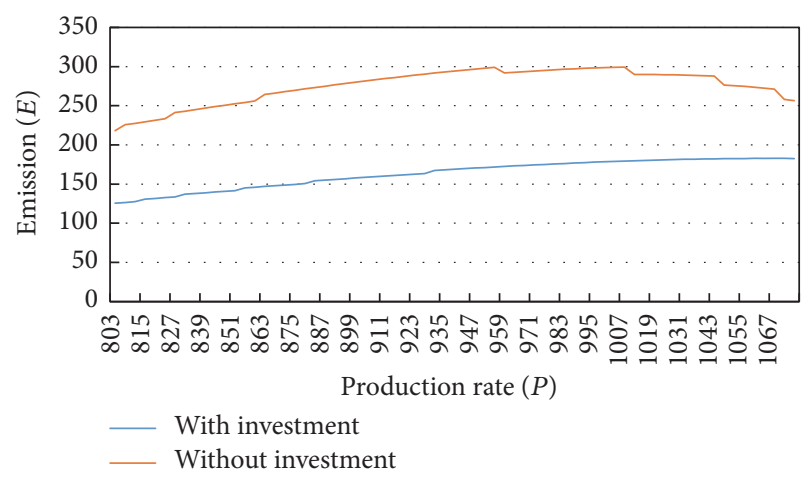

Figure 4: $P$ versus emission $(E)$.

technology is a special feature of this model. The author has further generalized the model by categorizing the customers as retail customers and wholesale customers and offering a fixed discount to wholesale customers on the regular selling price.

The following are some managerial insights from the developed model:

(i) Green investment has two benefits: it reduces emissions and partially offsets carbon tax to increase profit.

(ii) Carbon tax has negative effect on optimum profit.

(iii) Optimum profit is a concave function of the production rate. This is true for both the cases without green investment and with green investment.

(iv) Carbon tax has negative effect on GDP but positive effect on environment.

Unit cost parameters $m_{1}, m_{2}$, and $m_{3}$ and the emission reduction parameter $m$ can be estimated by linear regression after taking a logarithmic transformation. The parameters $\lambda_{1}$, $\lambda_{2}$ of $\lambda(P)$ can be estimated by linear regression.
If we substitute $K=0, \beta=0, C_{t}=0, \lambda=0$ in (10) and then take the limit as $P \rightarrow \infty$, we obtain $S^{*}=\sqrt{2 \alpha C_{s} / C_{h}}$. This is well-known economic lot size formula.

This model is solved by using the algorithm provided in Section 5. However, the model can be solved by any standard optimization techniques, like PSO, Jaya Algorithm (Rao [47]), and so on.

This model can be extended by incorporating inflation and time value of money. In this paper, carbon tax is considered as constant. A progressive carbon tax can be another possible direction to extend this paper. One can incorporate shortages (full, partial) in this model in the future.

\section{Conflicts of Interest}

The author declares that there are no conflicts of interest regarding the publication of this paper.

\section{References}

[1] https://climate.nasa.gov/effects/.

[2] P. D. Williams and M. M. Joshi, "Intensification of winter transatlantic aviation turbulence in response to climate change," Nature Climate Change, vol. 3, no. 7, pp. 644-648, 2013.

[3] https://ec.europa.eu/clima/policies/ets_en.

[4] https://www.c2es.org/docUploads/climate101-captrade.pdf.

[5] Z. Liu, T. D. Anderson, and J. M. Cruz, "Consumer environmental awareness and competition in two-stage supply chains," European Journal of Operational Research, vol. 218, no. 3, pp. 602-613, 2012.

[6] A. Ilic, T. Staake, and E. Fleisch, "Using sensor information to reduce the carbon footprint of perishable goods," IEEE Pervasive Computing, vol. 8, no. 1, pp. 22-29, 2009.

[7] A. Mukhopadhyay and A. Gowsami, "Economic production quantity models for imperfect items with pollution costs," System Science and Control Engineering, vol. 2, pp. 368-378, 2014.

[8] A. Toptal, H. Özlü, and D. Konur, "Joint decisions on inventory replenishment and emission reduction investment under different emission regulations," International Journal of Production Research, vol. 52, no. 1, pp. 243-269, 2014.

[9] G. X. Lou, H. Y. Xia, J. Q. Zhang, and T. J. Fan, "Investment strategy of emission-reduction technology in a supply Chain," Sustainability, vol. 7, no. 8, pp. 10684-10708, 2015. 
[10] T.-Y. Lin and B. R. Sarker, "A pull system inventory model with carbon tax policies and imperfect quality items," Applied Mathematical Modelling: Simulation and Computation for Engineering and Environmental Systems, vol. 50, pp. 450-462, 2017.

[11] H. Hu and W. Zhou, "A decision support system for joint emission reduction investment and pricing decisions with carbon emission trade," International Journal of Multimedia and Ubiquitous Engineering, vol. 9, no. 9, pp. 371-380, 2014.

[12] S. S. Sana, S. K. Goyal, and K. Chaudhuri, "An imperfect production process in a volume flexible inventory model," International Journal of Production Economics, vol. 105, no. 2, pp. 548-559, 2007.

[13] A. K. Manna, J. K. Dey, and S. K. Mondal, "Imperfect production inventory model with production rate dependent defective rate and advertisement dependent demand," Computers \& Industrial Engineering, vol. 104, pp. 9-22, 2017.

[14] M. Bonney and M. Y. Jaber, "Environmentally responsible inventory models: Non-classical models for a non-classical era," International Journal of Production Economics, vol. 133, no. 1, pp. 43-53, 2011.

[15] G. Hua, T. C. E. Cheng, and S. Wang, "Managing carbon footprints in inventory management," International Journal of Production Economics, vol. 132, no. 2, pp. 178-185, 2011.

[16] A. M. A. El Saadany, M. Y. Jaber, and M. Bonney, "Environmental performance measures for supply chains," Management Research Review, vol. 34, no. 11, pp. 1202-1221, 2011.

[17] M. I. M. Wahab, S. M. H. Mamun, and P. Ongkunaruk, "EOQ models for a coordinated two-level international supply chain considering imperfect items and environmental impact," International Journal of Production Economics, vol. 134, no. 1, pp. 151-158, 2011.

[18] Y. Bouchery, A. Ghaffari, Z. Jemai, and Y. Dallery, "Including sustainability criteria into inventory models," European Journal of Operational Research, vol. 222, no. 2, pp. 229-240, 2012.

[19] C. H. Glock, M. Y. Jaber, and C. Searcy, "Sustainability strategies in an EPQ model with price- and quality-sensitive demand," International Journal of Logistics Management, vol. 23, no. 3, pp. 340-359, 2012.

[20] S. Benjaafar, Y. Li, and M. Daskin, "Carbon footprint and the management of supply chains: Insights from simple models," IEEE Transactions on Automation Science and Engineering, vol. 10, no. 1, pp. 99-116, 2013.

[21] X. Chen, S. Benjaafar, and A. Elomri, "The carbon-constrained EOQ," Operations Research Letters, vol. 41, no. 2, pp. 172-179, 2013.

[22] D. Battini, A. Persona, and F. Sgarbossa, "A sustainable EOQ model: Theoretical formulation and applications," International Journal of Production Economics, vol. 149, pp. 145-153, 2014.

[23] S. Zanoni, L. Mazzoldi, L. E. Zavanella, and M. Y. Jaber, "A joint economic lot size model with price and environmentally sensitive demand," Production and Manufacturing Research, vol. 2, no. 1, pp. 341-354, 2014.

[24] N. Absi, S. Dauzère-Pérès, S. Kedad-Sidhoum, B. Penz, and C. Rapine, "Lot sizing with carbon emission constraints," European Journal of Operational Research, vol. 227, no. 1, pp. 55-61, 2013.

[25] N. Absi, S. Dauzère-Pérès, S. Kedad-Sidhoum, B. Penz, and C. Rapine, "The single-item green lot-sizing problem with fixed carbon emissions," European Journal of Operational Research, vol. 248, no. 3, pp. 849-855, 2016.

[26] H. Rosič and W. Jammernegg, "The economic and environmental performance of dual sourcing: A newsvendor approach,"
International Journal of Production Economics, vol. 143, no. 1, pp. 109-119, 2013.

[27] E. Arikan and W. Jammernegg, "The single period inventory model under dual sourcing and product carbon footprint constraint," International Journal of Production Economics, vol. 157, no. 1, pp. 15-23, 2014.

[28] V. Hovelaque and L. Bironneau, "The carbon-constrained EOQ model with carbon emission dependent demand," International Journal of Production Economics, vol. 164, pp. 285-291, 2015.

[29] C.-Y. Dye and C.-T. Yang, "Sustainable trade credit and replenishment decisions with credit-linked demand under carbon emission constraints," European Journal of Operational Research, vol. 244, no. 1, pp. 187-200, 2015.

[30] X. Chen and G. Hao, "Sustainable pricing and production policies for two competing firms with carbon emissions tax," International Journal of Production Research, vol. 53, pp. 64086420, 2015.

[31] J. M. C. Martí, J.-S. Tancrez, and R. W. Seifert, "Carbon footprint and responsiveness trade-offs in supply chain network design," International Journal of Production Economics, vol. 166, pp. 129142,2015

[32] M. S. García-Alvarado, M. Paquet, and A. Chaabane, "On inventory control of product recovery systems subject to environmental mechanisms," International Journal of Production Economics, vol. 165, article no. 5979, pp. 132-144, 2015.

[33] Z. Hong, C. Chu, and Y. Yu, "Dual-mode production planning for manufacturing with emission constraints," European Journal of Operational Research, vol. 251, no. 1, pp. 96-106, 2016.

[34] E. Bazan, M. Y. Jaber, and A. M. A. El Saadany, "Carbon emissions and energy effects on manufacturing-remanufacturing inventory models," Computers \& Industrial Engineering, vol. 88, pp. 307-316, 2015.

[35] X. Chang, H. Xia, H. Zhu, T. Fan, and H. Zhao, "Production decisions in a hybrid manufacturing-remanufacturing system with carbon cap and trade mechanism," International Journal of Production Economics, vol. 162, pp. 160-173, 2015.

[36] S. Papachristos and I. Konstantaras, "Economic ordering quantity models for items with imperfect quality," International Journal of Production Economics, vol. 100, no. 1, pp. 148-154, 2006.

[37] M. Ben-Daya, M. Hariga, and S. N. Khursheed, "Economic production quantity model with a shifting production rate," International Transactions in Operational Research, vol. 15, no. 1, pp. 87-101, 2008.

[38] A. Eroglu and G. Ozdemir, "An economic order quantity model with defective items and shortages," International Journal of Production Economics, vol. 106, no. 2, pp. 544-549, 2007.

[39] T. K. Datta, "An inventory model with price and quality dependent demand where some items produced are defective," Advances in Operations Research, vol. 2013, Article ID 795078, 2013.

[40] T. K. Datta, "Inventory system with defective products and investment opportunity for reducing defective proportion," Operational Research, vol. 17, no. 1, pp. 297-312, 2017.

[41] S.-T. Lo, H.-M. Wee, and W.-C. Huang, "An integrated production-inventory model with imperfect production processes and Weibull distribution deterioration under inflation," International Journal of Production Economics, vol. 106, no. 1, pp. 248-260, 2007.

[42] M. Khan, M. Y. Jaber, and M. Bonney, "An economic order quantity (EOQ) for items with imperfect quality and inspection 
errors," International Journal of Production Economics, vol. 133, no. 1, pp. 113-118, 2011.

[43] J.-T. Hsu and L.-F. Hsu, "An EOQ model with imperfect quality items, inspection errors, shortage backordering, and sales returns," International Journal of Production Economics, vol. 143, no. 1, pp. 162-170, 2013.

[44] P. Mandal and B. Giri, "A single-vendor multi-buyer integrated model with controllable lead time and quality improvement through reduction in defective items," International Journal of Systems Science: Operations \& Logistics, vol. 2, no. 1, pp. 1-14, 2015.

[45] S. S. Sana, "An economic production lot size model in an imperfect production system," European Journal of Operational Research, vol. 201, no. 1, pp. 158-170, 2010.

[46] X. Lai, Z. Chen, B. C. Giri, and C.-H. Chiu, "Two-echelon inventory optimization for imperfect production system under quality competition environment," Mathematical Problems in Engineering, vol. 2015, Article ID 326919, 2015.

[47] R. V. Rao, "Jaya: a simple and new optimization algorithm for solving constrained and unconstrained optimization problems," International Journal of Industrial Engineering Computations, vol. 7, no. 1, pp. 19-34, 2016. 


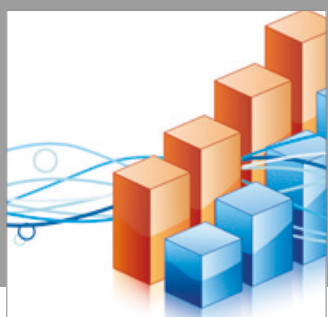

Advances in

Operations Research

vatersals

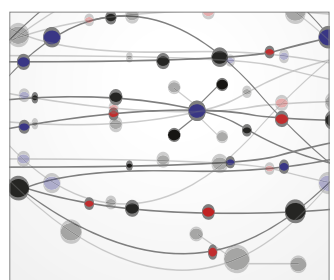

\section{The Scientific} World Journal
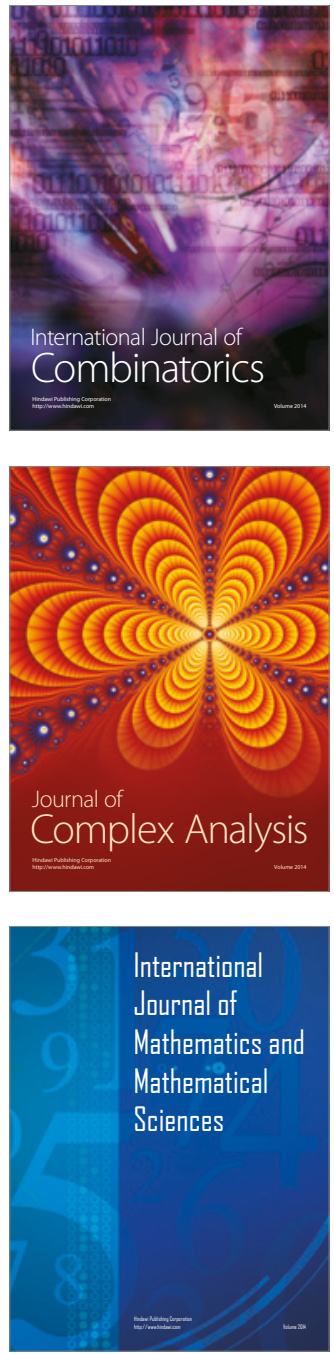
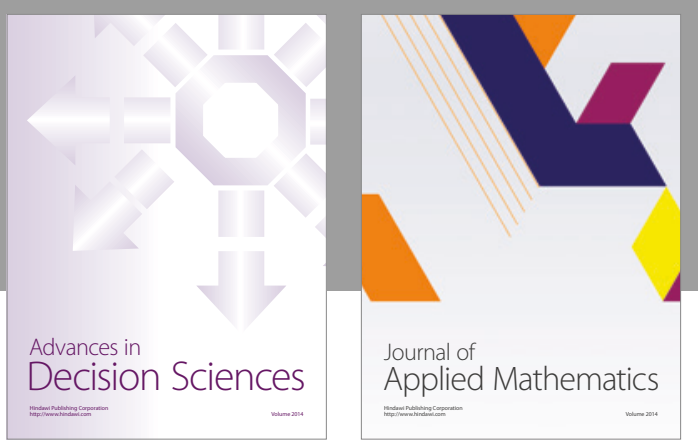

Algebra

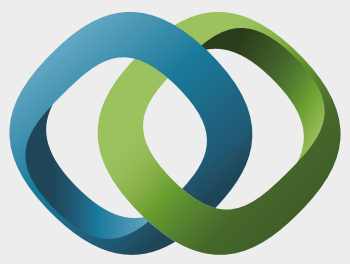

\section{Hindawi}

Submit your manuscripts at

https://www.hindawi.com
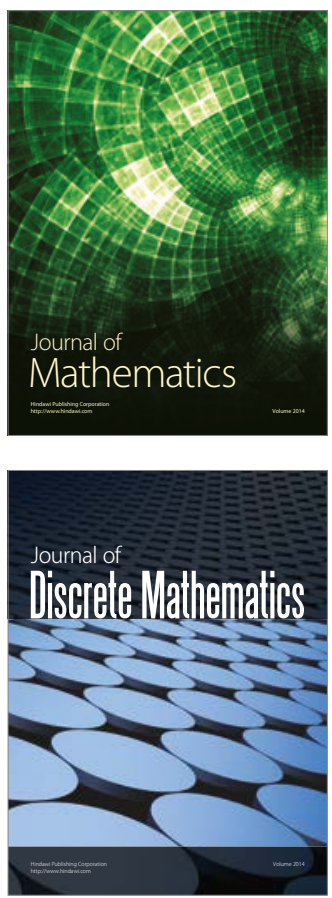

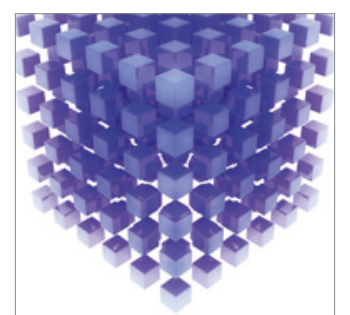

Mathematical Problems in Engineering
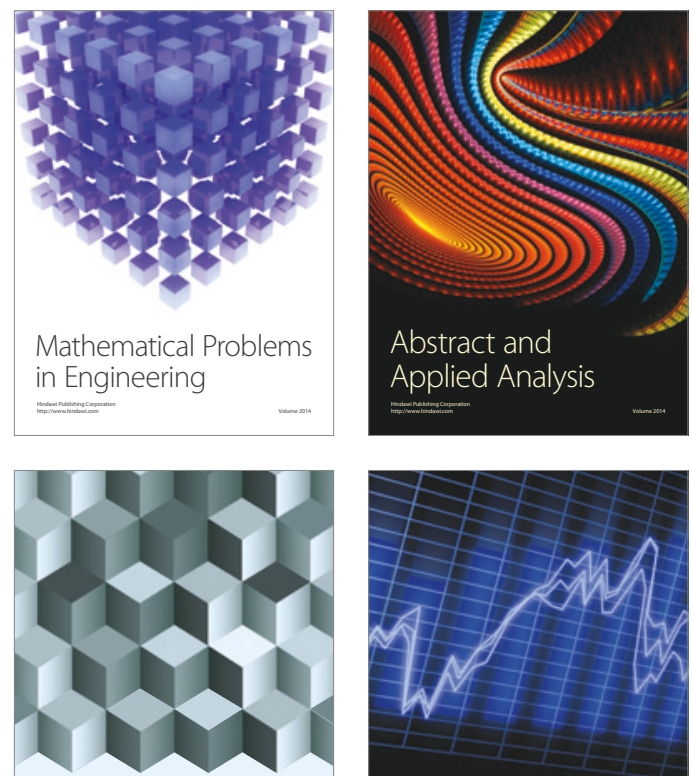

Journal of

Function Spaces

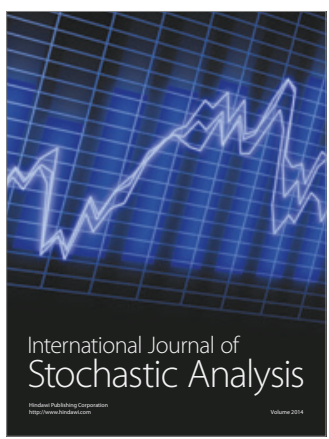

Probability and Statistics
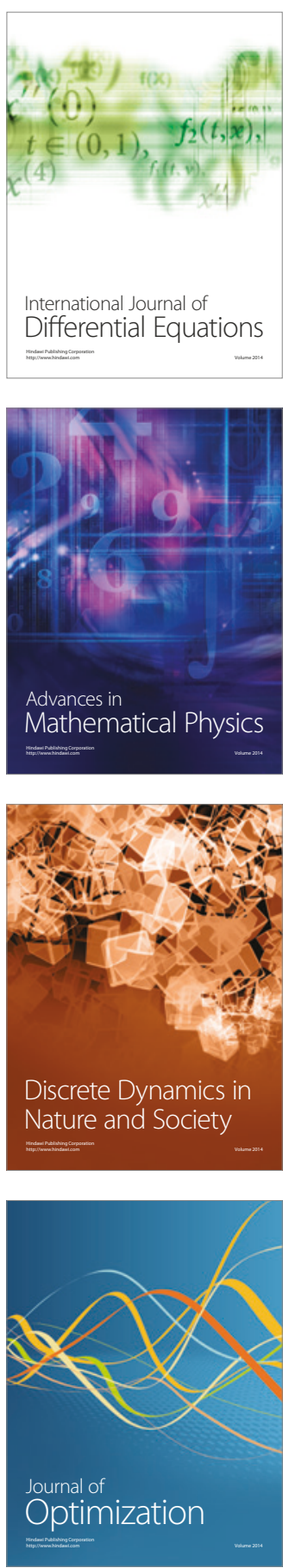